\title{
The Impact of the Use of a Virtual Three-Dimensional Learning Environment in Teaching Physics on the Achievement of the First Year Secondary Students and Their Attitudes toward It
}

\author{
Fadi Abdul Raheem Odeh Bani Ahmad
}

Faculty of Educational Science, Middle East University, Jordan

Received December 3, 2019; Revised January 19, 2020; Accepted February 7, 2020

Copyright $\odot 2020$ by authors, all rights reserved. Authors agree that this article remains permanently open access under the terms of the Creative Commons Attribution License 4.0 International License

\begin{abstract}
The purpose of this study is to explore the impact of the use of a virtual three-dimensional learning environment in teaching Physics on the achievement of the 1 st year secondary students and their attitudes toward it. This study was constructed on the quasi-experimental methodology. The study members were 60 students purposely selected from Jerash Secondary Comprehensive School for Boys and randomly divided into two groups as follows: 30 students as a control group and 30 students as an experimental group. To achieve the study's objectives, two instruments have been prepared: an achievement test and attitude scale. The instruments' validity and reliability have been assured as well. The study's results showed that there were significant differences at $(\alpha \leq 0.05)$ between the arithmetic mean's degrees of the experimental and control groups in support of the experimental group. The F-value was (65.689) which means rejecting the null hypothesis of the study. In light of the results, the students' attitudes were positive and high with a of $(0.27)$ and a mean degree of (3.93).
\end{abstract}

Keywords Virtual Three-Dimensional, Learning Environment, Physics, Achievement, Attitudes

\section{Introduction}

Virtual learning environments (VLE) represent stimulating and pioneering in the educational process, especially Three-Dimensional Environment (3DE) that have changed the learning process. This is because it is a digital learning source that allows the learner to act. The learner is at the center of the learning process by provided with an integrated multimedia environment that takes into account individual differences between learners. It also takes into consideration the temporal and spatial conditions of them who have the ability to self-learning, attracts learners, and increase their effectiveness and motivation to learn.

Cheong (2010) stressed that the virtual three-dimensional learning environment (V3DLE) are based on simulating reality to create interaction between learners and to motivate the learner's creativity and innovation. This is reflected in the development of learning outcomes, participation in the educational process, and interaction with virtual characters. In spite of the positive aspects of these environments, they also contain disadvantages. Among the disadvantages noted by Cheng and Wang (2011) are that these environments do not allow the follow-up of learners' activities. Therefore, these environments have been integrated into an e-learning (EL) system called Moodle (M)to form an open learning system based on supporting and stimulating the educational process in the virtual learning (VL).

Ghirardini (2011) noted that the (V3DLE) in which any physical presence of the real world can be simulated in a fictional world. (VL) provides the learner a fantasy world similar to the real tangible and perceived world. Most (VLE) are primarily visual experiences presented on the computer screen to include the simulation of sensory information such as sound and image, which contributes to the embodiment of the learner's knowledge and the continued existence of the effect on the process of learning and its outcomes.

To be more familiar with the role of 3-DV instruction environment played in the educational process, Florence and Parker (2014) indicated that the above-mentioned environment helps in making the efficiency of the learning process increase taking into account the individual differences among learners, and contributes to the 
organization of the learning environment and makes it a flexible interactive environment urging students to collaborative learning and participate in-class activities.

The communication between the elements of the education process through sound and image, chat and interactive whiteboards contributes to enhancing the learning process and the development of the cognitive, emotional and skill aspects of the learner. Goncalves, and Balacheff (2014) $\mathrm{VL}$, based on 3DE, can provide the effect of realism to support training and simulation, as was done by Ney, Chittaro and Buttussi (2015) Simulation practice also needs to be interactive with clear sequence and logic, as has been implemented in game-based 3D simulation.

Game-based learning is used to encourage learning activities by building on motivation, engagement, knowledge, and challenge through various technologies to achieve learning objectives (Liu \& Chen, 2013; Romero, Usart, \& Ott, 2015). Implementation technology in learning also improves learning and skill development while entertaining the user (Ricciardi \& De Paolis, 2014). Technology such as virtual world is designed to offer a real-world learning experience by providing real-time communication tools, interactive capabilities, and collaborative empowerment (Dickey, 2005; Kotsilieris \& Dimopoulou,2013).

The interactive learning environments are divided into two branches, one of which is the synchronized (VLE) [Al-Mendinger] (2009) pointed out that these are smart web-based learning sites with the basic elements of learning. It allows teachers and learners to meet at the same time. Others are asynchronous learning environments. This mode contributes to the organization of the learner and teacher's time in dealing with an asynchronous (VE) and freedom from the constraints of space and time where there is flexibility in choosing the appropriate time to be in the (VE) and access to learning content. This may be one of the reasons why educators go this type of technology research and study to identify the contributions that this technology can make in the field of education.

\subsection{Problem of the Study}

The results of previous studies emphasized the urgent need to develop the learning outcomes of learners by activating the so-called virtual instruction environments in the educational process. In their study, [Hussein] and [Adey] (2019) recommended further studies on the effect of using VL on students, especially in teaching Physics to achieve the students' aspired motivation and academic achievement. Besides, [Adey] (2017), CAN, Simsek (2015) [Al-Ajrami] (2013), and Barkand and Kush (2009) recommended to exploring the impact of (V3DLE) on the academic achievement attained by students.

To confirm this, the researcher conducted personal interviews in many schools where Physics teachers complain about the lack of learning outcomes among their students because of the difficulty of complex scientific concepts and abstract for the student. The (V3DLE) of Physics simulate dozens of experiments related to electrical and magnetic Physics, thermodynamics, electronics, modern Physics, nuclear experiments, mechanics, waves and many others, especially since the (3DLE). Provided with high-cost devices that are difficult to acquire in reality, teachers showed optimism that this technology would contribute to the development of learning outcomes of learners and increase their motivation and attitudes toward learning.

Against this, all the previous reasons prompted the researcher to conduct the current study to measure the impact of using the (3DLE) in getting the highest degree of academic achievement among the secondary stage learners in the Physics Course and their attitudes toward (VL).

\section{Objectives of the Study}

The purpose of the present research is to provide (V3DLE) to teach Physics to secondary school students to improve their level of achievement and measure their attitudes toward (VL). This aim can be attained by giving answers to these questions.

1. What is the impact of using (V3DLE) in teaching Physics on the academic achievement of students?

2. What are the attitudes among the student is toward (V3DLE)?

\section{Theoretical Framework and Previous Studies}

Ranilla, et al. (2014) pointed out (V3DLE) are modules to attain the aspired environment that allows learners to interact through them as they move in (VL) close to the real environment. Therefore, many studies have emphasized the significance of these environments, including an article by Bark and Kush (2009) which concluded that (VLE) support the achievement of the objectives of educational courses and promote participation in activities and achieve the goal of the communication process, especially in the case of groups. They also help to develop higher-order thinking skills and solve complex problems and support the development of core competencies defined by the educational framework. With that, the researchers pointed out the most.

\section{Important of These Studies Are}

In their 2014 study, (VL) for the First Experience in Dynamics, Re, and Giubergia aimed to apply simulation-based virtual laboratories to two groups to look their impact on the conceptual change of classical dynamics experiments in Physics. The first simulation was drafted to redefine the definition of the inertial mass process, and the second simulation determined the law between the powers of 
interaction. The experimental design was applied with the achievement test tool to find out the extent of correcting the concepts among Argentine students. The test was repeated for two years in "Universidad Technological National Faulted Regional Cordoba, Argentine". The students were divided into small groups to improve their cooperation. The results showed an improvement in the concept of inertia.

In their 2013 study, Tatli and Ayas have explored the impact of the virtual laboratory on academic achievement among a study sample of 90 Turkish ninth-graders who were divided into experimental group taught by the virtual laboratory and a control group taught by the traditional method. As for the study's instrument, it was an academic achievement test. The results showed that the effectiveness of the virtual laboratory method is similar to that of the normal laboratory method.

In their study, Tekbiyik and Ercan (2015) aimed at investigating the impact of the use of the virtual laboratory and traditional method on 60 Turkish fifth graders' achievement in Science, along with their attitudes toward them. Regarding data collection instruments, they were achievement test and questionnaire. The study's results showed no significant differences in students' attitudes and achievement between the two related groups.

In their study, Herga, Cagran, and Dinevsky (2016) aimed to examine the impact of the virtual laboratory on getting a better knowledge among (109) seventh grade learners in Chemistry. As for the study's instrument, it was an academic achievement test. The results showed certain number of significant differences in support of the experimental taught group using a virtual laboratory. This indicates that the virtual laboratory is the best way to acquire knowledge and achieve educational goals compared to the traditional method.

In his study, [Al-Sabahi] (2017) measured the impact of virtual tours on improving the cognitive achievement of the content of virtual tours and the attitude of students toward them. Two descriptive and experimental methodologies were adopted. The sample consisted of students of educational technology at Helwan University. As for the study instruments, they included an attitude scale and an achievement test concerning virtual tours. The results showed that there was a clear difference between the mean (M) Points of the control group using the traditional method and the (M) Points of the experimental group using virtual tours in the post-test scale related to cognitive achievement in favor of the experimental group. There was also a significant difference between the (M) Points of experimental group regarding pre and post measures to test cognitive achievement in support of the post measure. In post scale to measure students' attitudes toward using virtual tours, an experimental group has attained the difference.

Similarly, Faour and Ayoubi (2018) accomplished a research work on 50 students of the 10th aiming to evaluate the impact of the use of utilizing (VL) on notional understanding of the stream electric circuit and their states of mind in respect of physics subject. The statistical analysis and interpretation of the direct test marks results demonstrated that, after 10 weeks, the notional understanding of the stream electric circuit had markedly improved in both groups. In any case, the (M) mark of the exploratory bunch group was more significant than the control bunch. Otherwise, there was no significant distinction in students' attitudes in respect of physics subject between the two bunches.

In her 2018 study entitled "The Effectiveness of a (3DVE) Sloodle (S) in the Development of the Practical Experiments Skills in Physics of Secondary Students in Jeddah", Al-Shamrani has explored to what extent a (3DVE) plays a key role in strengthening the practical skills in the course of Physics among high school learners in Jeddah city in Saudi Arabia.

In her study, Al-Shamrani decided that using the semi-experimental method applies to the nature of the study. Due to the nature of the study, she has adopted a 2-part instrument, i.e. "Cognitive testing (pre and post) to measure the cognitive aspect of practical experience skills, test performance and note card (pre and post) to measure the performance side of practical experience skills" (AL-Shamrani,2018). With a study sample of a 40-learner from a female Saudi high school, the study sample was categorized into two groups as follows: a 20-learner experimental group using a (3DVE) (S) and 20-learner control group using a traditional method. As a conclusion of her work, she found that the (3DVE) (S) is considered to be completely effective in improving the cognitive aspect of the practical experience skills among female learners in the course of Physics in the Saudi city of Jeddah. The study also found that the (3DVE) (S) is considered to be completely workable to develop the practical side of the practical experiment skills among female learners in the course of Physics in the Saudi city of Jeddah. Another result was found is that "There was a statistically significant difference at the (M) level $(\alpha=0.05)$ between the (M) of the experimental group using a (VL) (S), which obtained an average of (15.50), and the average of the control group using the traditional method, which obtained an average of (11.15), in the post-test of cognitive test of practical experiences skills for the benefit of the experimental group (AL-Shamrani,2018). Based on the aforementioned results, Al-Shamrani has recommended activating the practical experiences through urging educational organizations to use the (VL) in several courses, strengthening the teachers with the required skills to factor in a (3DVE) in teaching educational courses, particularly physics, and raising the awareness among the educational staff of the Ministry of Education about the significance of the said environment in the educational process and its effective effect on the Saudi female learners level.

In another work, [Hussein] and [Adey] (2019) investigated the impact of a virtual laboratory on the basic stage learners in Physics' achievement in the Zarqa governorate compared to traditional techniques. A study sample was purposely 
selected from the study population with the use of a quasi-experimental methodology. The results showed zero significant differences because of the knowledge and method of teaching in using the software.

The current study is consistent with some of the previous studies in the methodology used in the research and in preparing the study instruments used to achieve its objectives. But what distinguishes the current study from previous studies is the handling of its variables. It examined the three-dimensional (VLE). They are more comprehensive than what has been addressed in previous studies, which are virtual laboratories. It was also characterized by the dependent variable, which is a variable of attitudes among learners toward (VL).

\section{Methodology}

Due to the nature of the study represented by measuring the effectiveness of the independent variable (teaching method) on the dependent variable (achievement development and student attitudes), the researcher has adopted the mixed approach. The mixed approach consists of the semi-experimental approach requiring selecting two groups: one of which is the experimental group which was taught the proposed unit of the physics course book entitled "Movement in One Dimension and Movement in Two Dimensions" through 3-DVLE (virtual classroom and virtual lab) and the control group which was taught the same unit but in the traditional method (the regular class through lecture, discussion, and the traditional laboratory). Secondly, the descriptive approach used to measure the training group students' attitudes towards learning through virtual learning environments, using a questionnaire developed by the researcher to attain this objective.

\section{Study Population}

This essential part consisted of all 1st-grade secondary learners enrolled in the academic year (2018/2019) in the Directorate of Education in Jerash governorate.

\section{Study Sample}

The key part of this study included (60) first-grade students in Jerash Comprehensive Secondary School for Boys. The sample was purposely selected because of the presence of three divisions of the first secondary grade, the cooperation of the school administration and Physics teachers with the researcher in facilitating the study procedures, as well as the availability of the appropriate environment for the application of study instruments.

\section{Study Instruments}

Because of the nature of the study in terms of its purpose, methodology, and population, the researcher prepared an achievement test in the proposed unit, entitled "Movement in One Dimension and Movement in Two Dimensions of the Physics Course". Theoretical literature and previous studies were reviewed to develop a questionnaire to measure students' attitudes toward VL. The study instruments were formulated in the final form after assuring their validity and reliability.

\section{Study Procedures}

The experimental and control groups were equally valued by applying the achievement test to ensure their consistency. Through arithmetic (M), (SD), and " $\mathrm{t}$ " value, the result was as presented in Table (1).

Table (1) presented a calculated value connected to (t-test) as (0.605). It was not significant at the scale of $(\alpha \leq 0.05)$, showing zero significant differences between two groups before application. This indicates the consistency of the two groups.

Table 1. Significance of Differences between Experimental and Groups in Pretest Achievement Test

\begin{tabular}{|c|c|c|c|c|c|c|c|}
\hline Levels & Group & Number & M & S.D. & DF & T-value & Level of Significance \\
\hline & Ex & 30 & 3.30 & 1.75 & \multirow{2}{*}{58} & \multirow{2}{*}{0.605} & No significance \\
\hline Total score & Co & 30 & 3.03 & 1.67 & & & \\
\hline
\end{tabular}




\section{Study Results and Discussion}

1. The main Results connected to answer of the first question that states: What is the impact of using the (3DVLE) in teaching Physics on the achievement?

To attain an answer to the aforementioned question, arithmetic (M) and SD deviations were calculated of experimental and control groups for their achievement in Physics as presented in Table (2).

Table 2. Arithmetic (M) and SD of Scores of Control and Experimental Groups in an Achievement Test

\begin{tabular}{|c|c|c|c|c|}
\hline Group & Number & $\begin{array}{c}\text { Expressive } \\
\text { statistics }\end{array}$ & Pre - test & Post - test \\
\hline \multirow{2}{*}{ Co } & 30 & $\mathrm{M}$ & 19.50 & 33.00 \\
\cline { 2 - 5 } & & $\mathrm{SD}$ & 6.59 & 3.71 \\
\hline \multirow{2}{*}{ Ex } & 30 & $\mathrm{M}$ & 20.73 & 42.40 \\
\cline { 2 - 5 } & & $\mathrm{SD}$ & 6.80 & 5.16 \\
\hline \multirow{2}{*}{ Total } & 60 & $\mathrm{M}$ & 20.12 & 37.75 \\
\cline { 2 - 5 } & & $\mathrm{SD}$ & 6.67 & 6.54 \\
\hline
\end{tabular}

Table (2) presents apparent differences concerning the (M) scores in the pre-tests and post-tests of the control and experimental groups. Results indicated presented (M) in the pre-test of a control group as (19.50) out of (50) Points with a (SD) of (6.59). The (M) of the pretest of the experimental group was (20.37) out of (50) with a (SD) of (6.80). This indicates the existence of an apparent difference in arithmetic (M) related to (1.23) Points in support of an experimental group. Besides, concerning the control group's post-test, it's (M) was (33.00) out of (50) Points with a SD of (3.71) in support of an experimental group. To know whether the difference of a (M) of the learners'

Control and experimental groups in post-application of the achievement test is significant at the significance level $(\alpha \leq$ 0.05 ), and to separate the difference between the aforementioned groups in the test's pre-test application, an Analysis of Common Variance (ANCOVA) was used. The results were as showed in Table (3).

The results in Table (3) presented a significant difference at the level of significance $(\alpha \leq 0.05)$ among the learners' $(M)$ scores of control and experimental groups, where the "F" value was (65.689). To determine the direction of related differences, adjusted (M) of scores of experimental and control groups were calculated in the achievement test in Physics as presented in Table (4).

The results in table (4) indicated that the adjusted post (M) for the control group is (32.985) and the adjusted post (M) for the experimental group is (42.515). There is a significant difference at the scale of $(\alpha \leq 0.05)$, among (M) scores of control and experimental groups in achievement test in Physics caused by using (VLE) in the instruction process in support of an experimental group.

Table 3. Analysis of Common Variance (ANCOVA) of Experimental and Control Groups in the pre achievement test

\begin{tabular}{|c|c|c|c|c|c|c|c|}
\hline $\begin{array}{c}\text { Source of } \\
\text { Variation }\end{array}$ & $\begin{array}{c}\text { Sum of } \\
\text { squares }\end{array}$ & $\begin{array}{c}\text { Degree of } \\
\text { freedom }\end{array}$ & $\begin{array}{c}\text { Mean of } \\
\text { squares }\end{array}$ & F-value & $\begin{array}{c}\text { Level of } \\
\text { significance }\end{array}$ & $\begin{array}{c}\text { ETA SQUARE } \\
\left(\eta^{2}\right)\end{array}$ & $\begin{array}{c}\text { Size of the } \\
\text { effect }\end{array}$ \\
\hline Pre - test & 1.573 & 1 & 1.573 & 0.077 & 0.783 & & \\
\hline Teaching method & 1350.568 & 1 & 1350.568 & 65.689 & 0.000 & 0.535 & Large \\
\hline Error & 1171.927 & 57 & 20.560 & & & & \\
\hline Total & 88031 & & 60 & & & & \\
\hline
\end{tabular}

Table 4. Adjusted Post (M) of Control and Experimental in in the post achievement test

\begin{tabular}{|c|c|c|c|}
\hline Group & Number & Adjusted post $-(\mathrm{m})$ & S.D. \\
\hline Co & 30 & 32.985 & 0.830 \\
\hline Ex & 30 & 42.515 & 0.830 \\
\hline
\end{tabular}


For knowing the size of an effect on the achievement of students, $\left(\mathrm{n}^{2}\right)$ was calculated. Its value was (0.535). According to Cohen standard, this value is between ( $\mathrm{f} \geq 0.40$ $\leq 1)$, i.e., the size of the effect of using a (3DVLE) in the achievement test in Physics.

The results showed a positive effect on the use of (V3DLE) on the achievement of students in teaching Physics. This is an indication of the importance of adopting a (V3DLE). With that, the present study is inconsistent with the study of [Al-Qahtanis] study (2010), [Al-Montashri] study (2011) and [Al-Ajrami] study (2013), which confirmed the importance of (VL) in improving students' cognitive achievement. This may explain the learner's self-determination to select the proper time for learning so that he can be able to select the proper time to develop and increase his achievement because the (V3DLE) provides an educational environment characterized by movement, image, and colors. It is an attractive and interesting environment suitable for students' tendencies and attitudes. The researcher may attribute this positive effect in increasing students' achievement that (V3DLE) illustrate abstract concepts especially, related to movements of different dimensions. This makes it easier for the student to visualize the imagination, which is reflected in understanding the applied aspects.

The current work's results differed from the study by Tekbiyik and Ercan (2015), and the study of [Hussein] and [Adey] (2019) that showed there were no significant differences of the virtual laboratory in academic achievement. Also, it has differed from Tatli and Ayas (2013) study, which concluded that the usefulness of virtual laboratory is similar to that of a regular laboratory. This may be attributed to the preference of a virtual learning strategy that is not limited to the virtual laboratory or the virtual class, but (V3DLE) that better simulates the abstract scientific phenomena and stimulating and exciting to learn students.

\section{Results Related to Answering the Second Question That States}

2. What are the attitudes among the students toward (V3DLE)?

To answer this question, (M), SD and ranks were calculated for study sample's estimates on the questionnaire that measure the attitudes of the student toward the (V3DLE). The results were as presented in Table (5).

Table 5. M, S. \& Ranks for Study Sample's Estimates Attitudes toward (3DVLE)

\begin{tabular}{|c|c|c|c|c|c|}
\hline No. & Item & $\mathbf{M}$ & S.D. & Rank & Degree \\
\hline 16 & I think that (VLE) helps self-evolution of learners. & 4.20 & 0.76 & 1 & Very high \\
\hline 3 & I think that (VL) takes into account individual differences between learners. & 4.13 & 0.73 & 2 & High \\
\hline 9 & $\begin{array}{l}\text { I think that learning and teaching using (VL) helps to quickly access to latest } \\
\text { information. }\end{array}$ & 4.07 & 0.64 & 3 & High \\
\hline 12 & (3DVL) motivates learning and teaching. & 4.07 & 0.74 & 3 & High \\
\hline 6 & $\begin{array}{l}\text { I feel fun when participating in online teaching programs using a (VLE) } \\
\text { strategy. }\end{array}$ & 4.03 & 0.85 & 5 & High \\
\hline 10 & $\begin{array}{l}\text { I think that learning and teaching through virtual learning applications } \\
\text { encourage learners to participate in educational activities. }\end{array}$ & 4.03 & 0.72 & 5 & High \\
\hline 4 & I think that (VL) neglects some elements of the educational process. & 4.00 & 0.64 & 7 & High \\
\hline 5 & I think that (VL) in teaching and learning increases the learner's confidence. & 3.97 & 0.72 & 8 & High \\
\hline 11 & I think that (VL) reduces the economic cost of education. & 3.93 & 0.78 & 9 & High \\
\hline 18 & $\begin{array}{l}\text { I think that teaching and learning should be mainstreamed using the (VL) } \\
\text { strategy for schools. }\end{array}$ & 3.93 & 0.87 & 9 & High \\
\hline 1 & $\begin{array}{l}\text { I think that learning based on (VL) activates social communication between } \\
\text { learners. }\end{array}$ & 3.90 & 0.66 & 11 & High \\
\hline 8 & $\begin{array}{l}\text { I believe that learning using (VL) contributes to overcoming many of the } \\
\text { problems of regular education. }\end{array}$ & 3.90 & 0.71 & 11 & High \\
\hline 20 & $\begin{array}{l}\text { I think that (VL) contributes to convey the effect of learning situations outside } \\
\text { the educational institution. }\end{array}$ & 3.90 & 0.88 & 11 & High \\
\hline 15 & I feel the importance of (VL) more than regular learning. & 3.87 & 0.68 & 14 & High \\
\hline 17 & (3DVL) applications motivate the learner to explore. & 3.87 & 0.73 & 14 & High \\
\hline 19 & $\begin{array}{l}\text { I believe that (3DVL) applications present information in a more interesting } \\
\text { way to learners than traditional education. }\end{array}$ & 3.87 & 0.78 & 14 & High \\
\hline 7 & The instruments available in (3DVL) develop thinking among learners. & 3.80 & 0.76 & 17 & High \\
\hline 14 & I feel comfortable when teaching and learning via (VL) applications. & 3.77 & 0.86 & 18 & High \\
\hline 13 & I believe that teaching through (3DVL)is teaching for the future. & 3.73 & 0.64 & 19 & High \\
\hline 2 & $\begin{array}{l}\text { I believe that teaching and learning through (3DVLE) applications reduces the } \\
\text { distractions of the educational process. }\end{array}$ & 3.70 & 0.75 & 20 & High \\
\hline \multicolumn{2}{|c|}{ Total score } & 3.90 & 0.27 & - & High \\
\hline
\end{tabular}


Table (5) presented the (M), in general, indicating positive attitudes toward (VL). The aforementioned (M) has been (3.93) with a SD of (0.27). It indicates that students' attitudes toward (VL) are positive.

\section{Conclusions}

This study's findings are along with studies of [Al-Sabahi] (2017) and [Al-Ajrami] (2013). In detail, item (16) that states "I believe that (VL) helps self-evaluation of learners" rank first with an arithmetic (M) of (4.20) and a SD of (0.70). As for item (3) that states, "I think that (VL) takes into account individual differences between learners", it ranked second with a (M) of (4.13) and a SD of (0.73). Regarding the item (9) that states "I think that learning and teaching using (VL) helps to quickly access to the latest information", it ranked third with a (M) of (4.07) and a SD of (0.64). Item (12) that states "VL motivates learning and teaching" came also in the third rank, with a (M) similar to the item (9) and a SD of (0.74). Yet, item (2) that states "I believe that teaching and learning through (3DVLE) applications reduce the distractions of the educational process" came in the final rank with a (M) of (3.70) and a SD of (0.75).

Of note, this study's results showed that the attitudes of first-grade secondary students toward the (3DVLE) were positive. This result may be due to the fact that the student may be satisfied with his needs during the learning process by relying on (3DVLE) strategy. The positive result in students' attitudes may be attributed to the student's love of collaborating with peers through the participatory and interactive learning environment provided by the (3DE) because teaching using (VL) has a comfortable psychological effect on students. It reduces the tension that accompanies students in understanding abstract concepts that can't be explained in the normal environment. This result may be attributed to the (3DVLE) that encourages the student to learn to discover what is unknown and abstract in the science of Physics.

\section{Recommendations}

Based on the aforementioned results, the following has been recommended:

- The entire educational bodies in Jordan should pay attention to the fact that each school has a virtual classroom with a (3DVLE).

- Organizing specialized training courses for Physics teachers to develop their skills in (VLE) Conducting studies on the use of (VLE) for outstanding students and late students.

\section{Acknowledgements}

The author is grateful to the Middle East University,
Amman, Jordan for the financial support granted to cover the publication fee of this research article.

\section{REFERENCES}

[1] [Adey], M. (2017). The Effect of Using the Virtual Laboratory on the Achievement and Motivation of the Basic Ninth Grade Students toward Science (Master's thesis). The Hashemite University, Jordan.

[2] [Al-Ajrami], S. (2013). The Effectiveness of a Proposed Program based on Virtual Classes in the Development of Some Effective Teaching Skills among Students in Jordanian Universities and their Attitudes toward them. Al-Manara Journal for Research and Studies, 19 (3). p315-350.

[3] [Al-Muntashri], H. (2011). The effectiveness of a proposed training program based on Virtual Classroom in developing effective teaching skills for forensic science teachers, (Master's thesis), Educational Diploma Program, King Abdul-Aziz University, Saudi Arabia.

[4] [Al-Qahtani], I. (2010). The Status of the using of virtual classrooms in distance learning program from the point of view of faculty members at King Abdul-Aziz University in Jeddah. (Master's thesis), Umm Al-Qura University. King Saudi Arabia.

[5] [Al-Sabahi], H. (2017). The Effectiveness of Virtual Rounds based on Text and Image in Developing Educational Technology Student's Achievement in Learning Resource Centers Course and their Attitudes toward those Tours. Educational Technology, (31), 87-137. Retrieved from $\mathrm{http}: / /$ search.shamaa.org/FullRecord?ID=124143.

[6] [Hussein], G., \& [Adey], (2019). The Effectiveness of Using Virtual Lab in Achieving Upper Basic Students in Physics in Jordan. Journal of Educational and Psychological Sciences, 20 (1), 503-532. Retrieved from https://journal.uob.edu.bh:4 43/handle/123456789/3505.

[7] Allmendinger, K., Kempf, F., \&Hamann, K. (2009). Collaborative Learning in Virtual Classroom Scenarios, European. 4th European Conference on Technology Enhanced Learning, (pp. 344-349) France. Doi:10.1007/978 -3-642-04636-0_33.

[8] Al-Shamrani, Alia Al Hamoud (2018): The Effectiveness of a $3 \mathrm{D}$ virtual environment (sloodle) in the development of the practical experiments skills in physics of secondary students in Jeddah, Journal of Educational \& Psychological Sciences, 8. (2). 2018.PP56-73.DOI: 10.26389/AJSRP.A190118.

[9] Barkand, J. \& Kush, J. (2009). Gears a 3D Virtual Learning Environment and Virtual Social and Educational World used in Online Secondary Schools. Electronic Journal of E-learning, 7(3), 215-224. Retrieved fromhttps://www.learnt echlib.org/p/55201/.

[10] Cela-Ranilla, J., Esteve-Mon, F., Esteve-González, V., \& Gisbert-Cervera, M. (2014). Developing self-management and teamwork using digital games in 3D simulations. Australasian Journal of Educational Technology, 30(6),634651. DOI: https://doi.org/10.14742/ajet.754

[11] Cheng, Y., \& Wang, S. (2011). Applying a 3D Virtual 
Learning Environment to Facilitate Student's Application Ability-The Case of Marketing Contents Lists. Computers in Human Behavior, 27(1), 576-584. Doi: 10.1016/j.chb.2010.1 0.008 .

[12] Cheong, D. (2010). The Effect of Practice Teaching Sessions in Second Life on the Change in Pre-service Teachers' Teaching Efficacy. Computers and Education, 55, (2), 868-880.

[13] Chittaro, L., \& Buttussi, F. (2015). Assessing knowledge retention of an immersive serious game vs. a conventional education method in aviation safety. IEEE Transactions on Visualization and Computer Graphics, 21(4), 529-538. https://doi.org/10.1109/tvcg.2015.2391853 .

[14] Dickey, M. D. (2005). Three-dimensional virtual worlds and distance learning: Two cases of active worlds as a medium for distance education. British Journal of Educational Technology, 36(3), 439-451. https://doi.org/10.1111/j.14678 535.2005.00477.x

[15] Faour, M.A. \& Ayoubi, Z. (2018). The effect of using virtual laboratory on grade 10 students' conceptual understanding and their attitudes towards physics. Journal of Education in Science, Environment and Health (JESEH), 4(1), 54-68. DOI: $10.21891 /$ jeseh.387482

[16] Florence, M. \& Parker, M.A. (2014). Use of Synchronous Virtual Classrooms: " why, who, and how?" University of North Carolina at Wilmington, Journal of Online Learning and Teaching. 10 (2), 192-210. Retrieved from. https://jolt.m erlot.org/vol10no2/martin_0614.pdf

[17] Gabbett, T., Jenkins, D., \& Abernethy, B. (2010). Physical collisions and injury during professional rugby league skills training. Journal of Science and Medicine in Sport, 13(6), 578-583.

[18] Ghirardini, B. (2011). E-learning methodologies: a guide for designing and developing e-learning courses. Rome. Food and Agriculture Organization of the United Nations.

[19] Herga, N., Cagran, B., \& Dinevski, D. (2016). Virtual Laboratory in the Role of Dynamic Visualization for Better Understanding of Chemistry in Primary School. Eurasia Journal of Mathematics Science and Technology Education, 12 (3),593-608. https://doi.org/10.1155/2014/787968.

[20] Kotsilieris, T., \& Dimopoulou, N. (2013). The evolution of E-learning in the context of 3D virtual worlds. Electronic Journal of e-Learning, 11(2), 147-167. Retrieved from https://files.eric.ed.gov/fulltext/EJ1012880.pdf.

[21] Liu, E., \& Chen, P. (2013). The effect of game-based learning on students' learning performance in science learning - A case of "conveyance go". Procardia - Social and Behavioral Sciences, 103, 1044-1051. https://doi.org/10.1016/j.sbspro.2 013.10 .430 .

[22] M. A. Ré., \& M. F. Giubergia. (2014). Virtual Laboratory for a First Experience in Dynamics. International Journal of Recent Contributions from Engineering, Science \& IT, 2(3), 27-32. DOI: 10.3991/ijes.v2i3.3820.

[23] Ney, M., Goncalves, C., \& Balacheff, N. (2014). Design heuristic for authentic simulation-based learning games. IEEE.Transactions on Learning Technologies,7(2), 132-141. https://doi.org/10.1109/TLT.2014.2316161.
[24] Ricciardi, F., \& De Paolis, L. (2014). A comprehensive review of serious games in health Professions. International Journal of Computer Games Technology, 2014(9), 1-11 https://doi.org/10.1155/2014/787968

[25] Romero, M., Usart, M., \& Ott, M. (2015). Can serious games contribute to developing and sustaining 21-century skills? Games and Culture, 10(2), 148-177. https://doi.org/10.1177/ 1555412014548919 .

[26] Tatli, Z. \& Ayas, A. (2013). Effect of a Virtual Chemistry Laboratory on Students' Achievement. International Forum of Educational Technology \& Society,.16(1), 159-170. Retrieved fromhttps://www.jstor.org/stable/jeductechsoci.16 .1.159? seq=1.

[27] Tekbiyik, A. \& Ercan, O. (2015). Effects of the Physical Laboratory vs. the Virtual Laboratory in Teaching Simple Electric Circuits on Conceptual Achievement and Attitudes toward the Subject. International Journal of Progressive education, 11(3), 77-89. Retrieved from https://www.researc hgate.net/publication/292604588.

[28] Tuncer CAN.\&Irfan Simsek. (2015). the use of 3D virtual learning environment in training ferine language Per-service teachers, Turkish Online Journal of Distance Education-TOJDE, 16(4), 114-124. Doi:10.17718/tojde.5301 2. 